\title{
Increasing Psychosocial Health with Cognitive Therapy in Schizoid Personality Disorder: A Single Subject Design
}

\author{
By Pawel D. Mankiewicz \& Julia C. Renton ${ }^{\dagger}$
}

\begin{abstract}
Schizoid personality disorder (SPD) has been characterised by a persistent detachment from, and indifference to, interpersonal relationships, alongside restricted range of expressed emotions, and limited rewards gained from social interactions, resulting in limited levels of socially healthy behaviour. Although the applicability of evidencebased psychological treatments, including cognitive therapy $(C T)$, has been indicated, there is a noticeable scarcity of relevant academic literature that might inform clinical practice in mental health clinics. This rigorous single subject design study attempts to address such apparent gap in literature. Sixteen sessions of CT were undertaken with an individual diagnosed with SPD and comorbid mood disorder in a community-based mental healthcare setting. Formal standardised measurement, behaviour frequency sampling, and subjective data were utilised to systematically evaluate the outcomes, indicating a considerable improvement in psychosocial functioning. The paper highlights the pertinence of cognitive and behavioural strategies in helping schizoid individuals address their interpersonal difficulties, reduce emotional distress, acquire socially inclusive behaviour, and ultimately increase their psychosocial health, without the need for explicitly intervening with their underlying personality traits.
\end{abstract}

Keywords: Behavioural change, Cognitive therapy, Psychosocial recovery, Schizoid personality disorder, Single subject design

\section{Introduction}

The availability of robust clinical and research literature on the subject of schizoid personality disorder (SPD) has been scarce. It seems that relatively few recognised cases of individuals with such diagnoses are seen within clinical services. As explained by Renton and Mankiewicz (2015), the reason for this might be twofold. First, for such individuals seeking psychological therapy would not be concordant with their belief sets. Second, after presenting to mental health services, such clients are likely to be allocated to inappropriate clinical pathways, in which they may be either incorrectly diagnosed or discharged once they are seen as not meeting diagnostic criteria for psychosis.

The American Psychiatric Association (2013) necessitate, in their DSM-5 diagnostic criteria for SPD, a longitudinal presence of detachment from, and indifference to, interpersonal relationships accompanied by a limited range of expressed emotions in social situations, as primary diagnostic features. Little interest is expressed in, or reward gained from, interactions with other people. Individuals with SPD are not troubled by the absence of relationships, but may be

*Clinical Teaching Fellow/Senior Clinical Psychologist, University College London/National Health Service, UK.

${ }^{\dagger}$ Clinical Director, National Health Service, UK. 
distressed by pressures from significant others due to the absence of interpersonal engagement. Additionally, The World Health Organization (1992), in their ICD10 criteria for SPD, reflected on a limited capacity to express positive and/or negative feelings toward others, excessive preoccupation with introspection, and insensitivity to prevailing social norms and conventions, as further key clinical indicators of such condition.

Renton and Mankiewicz (2015) highlighted additional distinct features of SPD, including pervasive patterns of detachment from relationships across all social contexts, withdrawn and solitary lifestyles, seeking little contact with others (from which virtually no satisfaction is gained), preference of solitary activities and occupations, marked restriction in display of affect, often lethargic and dysthymic mood in a generally moderately negative range, frequently slow and monotonic speech, rare changes in mood despite external events (with neither marked positive nor negative shifts), and limited interest in the development of close relationships of either sexual or platonic nature. Importantly, the authors argued that such symptomatology should be conceptualised on a continuum of experience, as should beliefs underlying and maintaining such presentation. Individuals might be considered as schizoid only when their personality traits become dysfunctional, significantly limiting a person's flexibility to make life adjustments and causing emotional distress.

This paper presents a single subject design study, which demonstrates how evidence-based cognitive and behavioural interventions might be utilised to help an individual with SPD overcome their interpersonal isolation, reduce emotional distress associated with collective exposure and, ultimately, increase their psychosocial health. Literature review is followed by a structured case presentation, description of methodology, systematic evaluation of outcomes, and discussion of the study's key implications for psychological medicine practitioners and researchers.

\section{Literature Review}

Literature indicates that individuals with SPD may fall into two distinct clinical subcategories, that is affect-constricted or seclusive, hence importance of differential diagnosis, particularly in relation to schizotypal and avoidant personalities (Triebwasser et al. 2012). Furthermore, the possibility of an experiential transition from SPD to psychosis, following an exposure to psychological crisis with insufficient coping abilities, was described by PerezAlvarez (2003). Consequently, Renton and Mankiewicz (2015) highlighted the importance of, and summarised clinical considerations related to the process of, differential diagnosis, in order to exclude overlapping clinical clusters of psychosis, delusional disorder, complex mood disorders, autism, and avoidant, paranoid and schizotypal personality disorders.

Epidemiological studies report the prevalence of SPD in general population as ranging from 0.7 (Samuels et al. 2002) to 4.5\% (Ekselius et al. 2001). However, empirical research often indicates a relatively low internal consistency of the diagnostic construct of SPD. For instance, SPD literature reviewed by Mittal et 
al. (2007) reported Cronbach alpha coefficients between 0.47 and 0.68 , while other studies appear to have demonstrated insufficient sample size affecting statistical analyses (Farmer and Chapman 2002).

The importance of a comprehensive understanding of clinical presentations of SPD and effective psychological treatments for this condition also appears relevant within the context of prevention of risky and antisocial behaviour. A scoping review published recently by the Offender Health Research Network (2012) indicated that a high proportion of individuals coming into contact with the criminal justice system may present with a diagnosable personality disorder. The prevalence of SPD among convicted persons with a diagnosis of personality disorder was shown to approximate $11 \%$ (Coid 2002).

People with SPD appear to rarely come to the attention of mental health services, unless their behavioural and emotional detachment begins causing considerable distress to them or to their families (Fagin 2004). Even then, such individuals would seldom adopt an active interest in their psychosocial recovery, thus collaborative therapeutic relationship and functional therapeutic alliance seem less likely to develop (Adshead and Sarkar 2012). Such avoidance of psychological help might be seen as a barrier to the utilisation of empirically sound interventions among individuals with SPD. Furthermore, a considerable comorbidity between severe personality disorders, including schizotypal, and mood disorders, in particular depression (Stevenson et al. 2011), might further impair help seeking behaviour among individuals requiring psychotherapeutic support.

Although complex personality disorders have at times been regarded as untreatable (Davison 2002), some contrary evidence may also be found, particularly concerning the utilisation of cognitive behavioural therapy targeting emotional distress and unhelpful beliefs associated with such disorders (Bateman and Tyrer 2004). A randomised study conducted by Joyce et al. (2007) demonstrated that SPD had no adverse effect on treatment response to cognitive behavioural therapy (CBT) for depression, even though the effectiveness of interpersonal therapy appeared considerably decreased. Considering significant difficulties that might occur in the development of a functional and collaborative therapeutic relationship reflecting interpersonal and social components of SPD, such results appear encouraging.

The fundamental principle of CBT for complex personality disorders, as explained by Evershed (2011), is the formation of a functional therapeutic alliance. Such process would be initiated at the beginning of therapy and should focus on the development of mutual understanding of reported difficulties (formulation), eventually leading to the establishment of trust and collaboration. In the latest edition of Cognitive Therapy of Personality Disorders edited by Beck et al. (2015), a structured model of cognitive therapy (CT) for SPD was proposed (Renton and Mankiewicz 2015). The treatment course included the following treatment modules: first, eliciting trust within therapy by exploring ambivalence, respecting the client's autonomy and emotional boundaries, and remaining nondefensive; second, exploring the impact and accuracy of unhelpful beliefs about others in key interpersonal and social contexts, and working collaboratively to 
develop alternative, more balanced beliefs; and third, experimenting with adaptive social behaviours and skills to support the development of new, functional beliefs.

\section{Method}

This study employs a single subject clinical research design. The case study follows a robust intervention protocol and evaluates outcomes using standardised and validated psychological measurement, behaviour frequency sampling, and subjective reflections.

\section{Case Presentation}

The present single subject case study describes a structured and methodologically rigorous clinical implementation of CT treatment model for SPD and attempts to address the apparent scarcity of clinical literature on the subject of psychological interventions for individuals with schizoid personalities and associated emotional distress. Formal consent for case study to be written and utilised for educational and publishing purposes has been obtained from the service user. A pseudonym is used to protect the client's identity.

\section{Presenting Complaints and Background History}

Richard was a 40 year old man of white Caucasian origin, referred to a specialist community service for adults with complex mental health needs in one of the National Health Service Trusts, East of England, UK. Prior to the commencement of psychological treatment, a number of ongoing distressing symptoms were reported, including chronically low mood and dysphoria, pervasive melancholia and anhedonia, negative introspection, anxiety, a sense of interpersonal vulnerability experienced in social contexts, and prolonged social avoidance and disengagement.

Richard had completed an undergraduate degree in fine arts in his early 20 's, yet soon presented to mental health services when he became increasingly concerned about his alcohol use, through which he attempted to manage his escalating mood difficulties. He was then diagnosed with depression and SPD in his mid-twenties and treated pharmacologically with antidepressants for numerous years. Richard described feeling low in mood for as long as he could recall and was unable to recount any happy times. He agreed with his diagnosis of SPD and described an overall lack of interest in the development and maintenance of any relationships of both platonic and intimate nature. Richard described having taken some comfort in the diagnosis of SPD, seeing it as normalising of his unique character and, while still low in his mood, he had disengaged from pharmacological treatments following the assignment of such diagnosis. At that point, he was able to stop drinking and has since maintained his abstinence from psychoactive substances.

Richard recalled witnessing frequent incidents of domestic violence in his childhood and adolescence, perpetrated toward his mother and siblings. $\mathrm{He}$ 
explained he did not attract aggressive behaviour from his father and attributed this to his quietness, shyness and interpersonal avoidance, being the only child who had withdrawn from domestic conflicts. As a result, he perceived his disengagement as a survival strategy which had served him well in his early years. Yet, despite his life-long avoidance of interpersonal interaction, Richard remembered being able to enjoy solitary activities (e.g. creative arts) and led a relatively functional life in the past (e.g. while working as a painter and sculptor).

However, in the recent years Richard had noticed his mood becoming gradually lower as he had become increasingly more preoccupied with negative introspection, eventually disengaging from activities which had previously been rewarding. The current contact with mental health services had been precipitated by the declining health of his parents and growing pressure to coordinate the provision of their health care. This had greatly increased his anxiety and he reported feeling unable to cope.

\section{Assessment and Evaluation Methodology}

To formally assess Richard's symptomatic presentation and evaluate the intervention outcomes, a self-report questionnaire, Brief Symptom Inventory (BSI), was administered with the client. The BSI reflects symptom patterns among people with mental ill-health and is scored on nine clinical subscales (Derogatis and Melisaratos 1983). The measure has been standardised and validated on large normative samples in the United States (Derogatis and Melisaratos 1983), in the United Kingdom (Francis et al. 1990, Ryan 2007), and internationally (Kerimova and Osmanli 2016, Pereda et al. 2007), and was shown to demonstrate sufficient psychometric properties. Internal consistency was established using Cronbach alpha coefficients for all nine dimensions, which ranged from 0.71 to 0.85 , while test-retest reliability coefficients were estimated between 0.68 and 0.91 (Derogatis 1993). Internal structure and construct validity was found to be sufficient: orthogonal varimax loadings determined from principal components analysis ranged from 0.35 to 0.71 . Convergent and discriminant validity was examined through comparison with the Minnesota Multiphasic Personality Inventory; correlation coefficients scoped from 0.31 to 0.72 (Derogatis 1993). The BSI has also been reliably utilised to measure psychological distress associated with serious physical illnesses (Ruz et al. 2010).

For the purpose of Richard's assessment, the BSI subscales of depression (DEP) and anxiety (ANX) were administered to reflect emotional concerns voiced in assessment. Richard's pre-intervention DEP score was 3.00 while his ANX score was 2.83 , both increased by approximately one standard deviation above the UK outpatient mean, indicating elevated levels of emotional distress on both subscales. Furthermore, to formally measure Richard's experiences of interpersonal vulnerability, the BSI subscale of interpersonal sensitivity (I-S) was also administered, resulting in pre-intervention score of 3.25, which exceeded the UK outpatient mean by one standard deviation. 


\section{Case Conceptualization}

As presented in Figure 1, the cognitive model of SPD with associated emotional distress and safety behaviour (Renton and Mankiewicz 2015) was utilised to formulate Richard's experiences of emotional and interpersonal difficulties.

Figure 1. Diagrammatic Case Formulation (Renton \& Mankiewicz 2015)

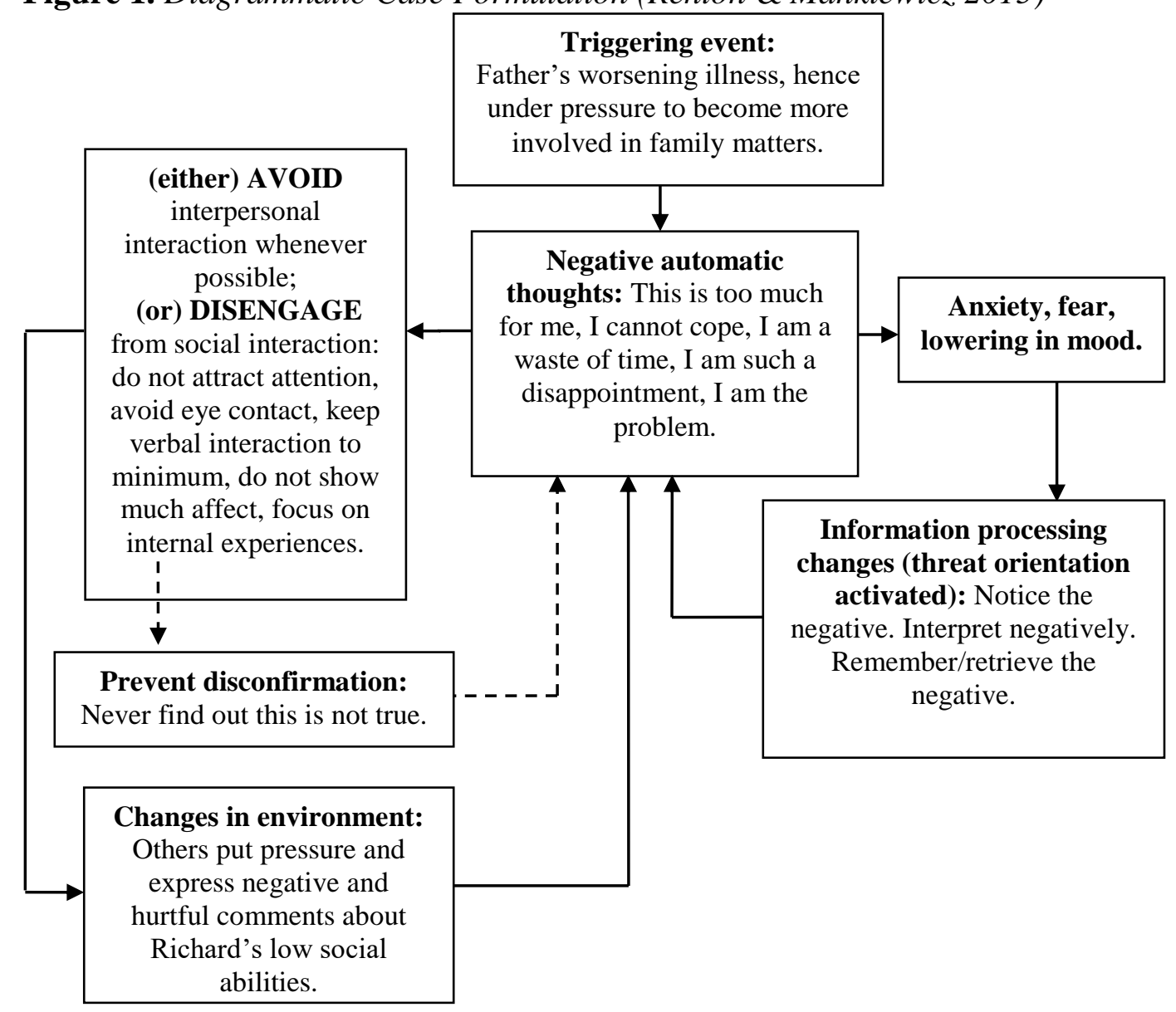

A considerable link between adverse childhood experiences and the development of personality disorders has been demonstrated in a longitudinal study conducted by Johnson et al. (2000). As explained by Renton and Mankiewicz (2015), individuals with SPD may often recall early experiences of being perceived as different from their family, or in some way less able than others. As a result, they may internalise a view of themselves as negatively different (core beliefs about self), perceive others as unkind and unhelpful (core beliefs about others), and appraise social interaction as difficult and damaging (core beliefs about the world). Consequently, a set of intermediate assumptions may be formed leading to the utilisation of unhelpful safety behaviours, maintaining a socially disengaged lifestyle.

In Richard's case, his early experiences of witnessing domestic violence had been coped with through a gradually more pronounced social disengagement, 
interpersonal withdrawal, and lack of emotional expression, which in time have become somewhat pervasive in his presentation ("I was always quiet, shy and withdrawn, really well-behaved and did not draw attention to myself"). Although perceived as an effective survival strategy, such withdrawal often attracted personally negative comments from significant others (who would suggest that he was "weak", "weird", "had no guts" and were letting them all down), which with time became internalised and formed a set of core beliefs about self ("I'm such a disappointment, I'm a waste of time"). These were reflected in situation-specific negative automatic thoughts, resulting in emotional distress and activating habitual safety behaviour (avoidance and disengagement). Such responses were in turn maintained by threat-focused information processing changes, prevention of disconfirmation of unhelpful cognitions, and unsupportive environmental reactions (further negative comments).

\section{Course of Treatment}

In total, 16 sessions of cognitive behavioural treatment were undertaken with Richard, initially weekly, then fortnightly, and were facilitated in an outpatient mental health clinic by an experienced clinical psychologist with an expertise in cognitive behavioural psychotherapy. The intervention plan was based on CT for SPD treatment model (Renton and Mankiewicz 2015), hence incorporated three subsequent core intervention modules: addressing ambivalence and establishing therapy goals, cognitive restructuring of unhelpful beliefs, and behavioural experiments addressing social interaction.

\section{Addressing ambivalence and establishing goals}

The initial treatment module began with exploring Richard's ambivalence about participating in therapy and eliciting working alliance (session 1). This process was entirely embedded in Socratic dialogue (Padesky 1993), thus allowing the client explore his own perception of advantages and disadvantages of engaging in the process of change, all while supporting the client's individuality. Although Richard initially communicated his pessimism about own recovery, he eventually reflected on his need to return to a considerably more functional life and expressed his understanding that therapy might initiate the process of gradual change or (more realistically for Richard at the time) would be unlikely at least to cause an increase in his distress.

The treatment then progressed toward establishing a list of personally meaningful and psychosocial recovery oriented goals (sessions 2-3). Difficulties in negotiating a collaborative problem and goal list with a schizoid client might commonly occur, as such it is important to elucidate what particular elements of their experience are subjectively problematic to the client; this may often differ markedly from what the therapist expects the area of concern to be for those with such presentation (Renton and Mankiewicz 2015). In Richard's opinion his social indifference was not pertinent to his own wellbeing, but rather his disengagement from previously rewarding activities had eventually led to the lowering in his mood and (along with the expectations of co-ordinating the provision of family healthcare) had exacerbated his interpersonal anxiety. Hence, the following 
intervention goals were agreed on: learning to disengage from self-defeating introspection and unhelpful cognitions about self, restoring engagement with personally rewarding activities, and planning for (and coping with) task-oriented interaction with others.

\section{Cognitive restructuring of unhelpful beliefs}

This treatment module focused on exploring the impact and accuracy of unhelpful beliefs in key interpersonal and social contexts, and working collaboratively to develop more balanced and self-compassionate appraisals of own functioning (sessions 4-10). Interventions included guided discovery, evidential analysis, generation of alternative explanations, and utilisation of functional self-statements and self-affirmations.

Richard was unable to find evidence supporting his anxiety-inducing beliefs about engaging in necessary task-focussed interactions with others ("This is too much for me, I cannot cope"). Contrary to such unhelpful preditions, Richard reflected on numerous experiences of engaging in tasks requiring interpersonal interaction and, despite anxiety, recalled coping well and achieving desired outcomes. Following the instillation of the initial doubt in self-defeating beliefs (which appeared important in achieving the metacognitive shift in lowering the certainty he held about these), cognitive restructuring gradually proceeded toward the reattribution of negative beliefs about self. In this stage, Richard developed a more compassionate understanding of functional links between early life experiences, i.e. frequent exposure to negative and verbally abusive statements from significant others, and subsequent internalisation of such comments in the form of core beliefs about self. To counterbalance Richard's unhelpful interpretations of his interpersonal competencies, (e.g. "I can't do it, I can't cope") he began implementing a range of compassionate self-statements, and practiced reframing his pre-existing appraisals with evidence-informed self-affirmations (e.g. "Not everyone takes pleasure in interpersonal activities but I have shown that I can achieve my goals even when I need to interact with others").

Behavioural experiments addressing social interaction

As cognitive restructuring module resulted in a considerable progress in Richard's psychosocial recovery, the treatment subsequently progressed toward the utilisation of behavioural intervention (sessions 11-16). This behaviourally oriented module involved active and systematically planned experimentation with adaptive social behaviours (those that were useful and task-oriented) to further support the development of helpful beliefs. As any socially oriented task is likely to trigger anxiety and further interpersonal avoidance among individuals with SPD (Renton and Mankiewicz 2015), this series of experiments was employed as a sequence of collaboratively pre-arranged graded exposure tasks.

Alongside this, behavioural activation focused on enabling Richard to reengage with a range of subjectively rewarding activities (e.g. creative arts, gardening, reading biographies), thus facilitating re-introduction of experiences of enjoyment. Simultaneously, behavioural experiments were planned and implemented gradually to ensure brief exposure to interpersonal tasks with clearly defined and achievable goals (e.g. attending a medical appointment with a family 
member, visiting local library and gallery, supporting family in house chores). The underlying assumption of the protective importance of avoidance and withdrawal from interpersonal contact was reframed in small subsequent stages, eventually resulting in Richard's consideration of an alternative appraisal ("Although I find interacting with others rather difficult, I can still do it and achieve some desirable outcomes").

Gradually, Richard's conviction in the accuracy of tested assumptions reduced, leading to relaxation of safety behaviours. Importantly, Richard reported that his re-engagement with personally rewarding activities improved his overall life satisfaction, while regular involvement in structured interpersonal tasks distracted his negative introspection and helped him dispute his self-defeating beliefs. Richard expressed being able to "do the things I need to without worrying endlessly".

\section{Evaluation of Outcomes}

Table 1. Subjective pre- and post-Intervention Reflections on Presenting Difficulties

\begin{tabular}{|c|c|c|}
\hline & Pre-intervention Quotes & Post-intervention Quotes \\
\hline $\begin{array}{l}\text { Interpersonal } \\
\text { Interaction }\end{array}$ & $\begin{array}{l}\text { This is too much for me, I } \\
\text { cannot cope with it. I just } \\
\text { need to keep myself } \\
\text { inconspicuous; it's my } \\
\text { recipe for my own silent } \\
\text { existence. }\end{array}$ & $\begin{array}{l}\text { Although I find interacting with others } \\
\text { rather difficult, I can still do it and achieve } \\
\text { some desirable outcomes. I understand I } \\
\text { have to engage in social interaction in order } \\
\text { for my perceptions to change. I don't feel I } \\
\text { need to run from every conversation } \\
\text { anymore. I have a capacity to experience } \\
\text { these brief feelings of overcoming the } \\
\text { limitations of my own self-restraint. }\end{array}$ \\
\hline $\begin{array}{l}\text { Subjectively } \\
\text { Rewarding } \\
\text { Activities }\end{array}$ & $\begin{array}{l}\text { I feel utterly unable to } \\
\text { return to all those very few } \\
\text { things I used to enjoy in my } \\
\text { life. }\end{array}$ & $\begin{array}{l}\text { I cannot be dismissive about basic things } \\
\text { that are so necessary in my life. I recognise } \\
\text { that finding courage to do it will give me } \\
\text { positive feedback about myself and I will } \\
\text { eventually feel better. I've realised I had an } \\
\text { ability to break up of being passive and take } \\
\text { an active initiative in managing my own } \\
\text { wellbeing. }\end{array}$ \\
\hline $\begin{array}{l}\text { Self- } \\
\text { Defeating } \\
\text { Introspection }\end{array}$ & $\begin{array}{l}\text { I always find myself in the } \\
\text { middle of this perpetual } \\
\text { negative intellectual analysis } \\
\text { of my own functioning and } \\
\text { life circumstances. It's } \\
\text { relentless. }\end{array}$ & $\begin{array}{l}\text { I'm not harming myself mentally anymore, } \\
\text { I'm not being so unnecessarily critical. I } \\
\text { feel like I'm able to gain some distance } \\
\text { toward my own negativity. It's not that } \\
\text { intimidating anymore, it's not that } \\
\text { overwhelming. }\end{array}$ \\
\hline Mood & $\begin{array}{l}\text { I feel resistant to the idea of } \\
\text { change as nothing has ever } \\
\text { really worked for me. I just } \\
\text { need to accept the fact that I } \\
\text { don't experience pleasure in } \\
\text { my life to the extent that } \\
\text { other people do. I'm just } \\
\text { naturally a very sad human } \\
\text { being I guess. }\end{array}$ & $\begin{array}{l}\text { I recognise I'm feeling generally better, } \\
\text { more in connection with life and the world. } \\
\text { I have a more tangible and clearer vision of } \\
\text { life and I acknowledge that it is my } \\
\text { decision of what to expect of each day. I } \\
\text { have more optimism about things working } \\
\text { out now. I don't remember having it before. } \\
\text { Good things might happen. }\end{array}$ \\
\hline
\end{tabular}


As comparatively encapsulated in Table 1, at the end of therapy Richard reported a range of subjectively substantial improvements in his psychosocial functioning.

Furthermore, as illustrated in the comparative pre- and post-intervention behavioural frequency samples (Table 2), objective improvements in Richard's abilities to cope, that is achieving a substantial relaxation of his safety behaviours and increasing engagement with personally rewarding and individually meaningful activities, were achieved as well.

Table 2. Self-reported Frequency of Safety Behaviour and Subjectively Rewarding Activities

\begin{tabular}{|l|l|l|}
\hline & Pre-Intervention & \multicolumn{1}{|c|}{ Post-Intervention } \\
\hline $\begin{array}{l}\text { Interpersonal } \\
\text { Disengagement }\end{array}$ & $\begin{array}{l}\text { Continuous } \\
\text { disengagement } \\
\text { Social Avoidance }\end{array}$ & $\begin{array}{l}\text { Daily task-oriented interaction } \\
\text { with family members (e.g. house } \\
\text { chores and leisure activities) } \\
\text { and others (e.g. discussions } \\
\text { about arts and literature) }\end{array}$ \\
\hline $\begin{array}{l}\text { No Eye-Contact, Keep Head } \\
\text { Down }\end{array}$ & $\begin{array}{l}\text { Continuous } \\
\text { avoidance of social } \\
\text { interaction }\end{array}$ & $\begin{array}{l}\text { Weekly lunch in a cafe with } \\
\text { interpersonal } \\
\text { interactions } \\
\text { pursuit of socially inclusive } \\
\text { activities (e.g. cycling groups) }\end{array}$ \\
\hline $\begin{array}{l}\text { Focus on Internal } \\
\text { Experiences }\end{array}$ & $\begin{array}{l}\text { Initiates and maintains eye } \\
\text { contact regularly in verbal } \\
\text { interpersonal interactions }\end{array}$ \\
\hline $\begin{array}{l}\text { Daily, perceived as } \\
\text { negative, perpetual, } \\
\text { and relentless }\end{array}$ & $\begin{array}{l}\text { Daily, yet perceived as } \\
\text { intermittent, manageable, } \\
\text { distractible, and increasingly } \\
\text { affirmative }\end{array}$ \\
\hline $\begin{array}{l}\text { Reading Biographical } \\
\text { Literature }\end{array}$ & $\begin{array}{l}\text { Last attempted } \\
\text { approx. one year } \\
\text { ago }\end{array}$ & $\begin{array}{l}\text { Daily, with an ultimate goal to } \\
\text { return to an arts and crafts } \\
\text { profession }\end{array}$ \\
\hline Gardening & $\begin{array}{l}\text { Approx. once a } \\
\text { month }\end{array}$ & Daily, in the evening \\
\hline
\end{tabular}

Finally, as presented in Table 3, the post-treatment standardised measurement confirmed the considerable reduction in both depression and anxiety levels, and demonstrated a marked improvement in the levels of interpersonal sensitivity. All post-intervention outcome scores fell within approximately one standard deviation range below the UK outpatient mean.

Table 3. Standardised Measurement: BSI pre-Treatment (Assessment) and PostTreatment (Outcome Evaluation) Scores

\begin{tabular}{|c|c|c|c|}
\hline BSI scale & UK outpatient mean/SD & Pre-treatment score & Post-treatment score \\
\hline DEP & $\mathrm{M}=1.99 / \mathrm{SD}=1.10^{*}$ & 3.00 & 1.33 \\
\hline ANX & $\mathrm{M}=1.87 / \mathrm{SD}=1.03^{*}$ & 2.83 & 1.17 \\
\hline $\mathbf{I}-\mathbf{S}$ & $\mathrm{M}=2.08 / \mathrm{SD}=1.22^{*}$ & 3.25 & 1.25 \\
\hline
\end{tabular}

(*) As reported by Ryan (2007). 


\section{Follow-up}

While evaluating the effectiveness of psychotherapeutic interventions, it appears helpful to adopt a quasi-experimental A-B-A design (Backman and Harris 1999), in which the effects of completed psychological treatment would be reevaluated by a follow-up administration of all outcome measures. Although the A$\mathrm{B}$ design has been broadly accepted as a sufficient methodology for conducting clinical case studies (Backman et al. 1997), allowing sufficient time to elapse following the withdrawal of therapeutic support would permit a more methodical evaluation of long-term effects of such treatment.

At the time of closing the case, Richard reported considerable progress in his overall functioning and a significant reduction in his clinical symptoms, as reflected in Tables 1-3. Six months after formally completing the intervention, a telephone booster session was arranged to monitor Richard's ongoing progress in his psychosocial recovery. He reflected on the continuing utilisation of cognitive and behavioural coping strategies he had developed in his therapy. Richard described his mood as stable and rather positive, and reported a continuous absence of experiences of depression or intense anxiety. He maintained his regular engagement in subjectively rewarding activities and was undertaking steps toward returning to formal employment. Although Richard stated he was still experiencing a level of discomfort in social contexts, the sense of interpersonal vulnerability appears to have been replaced with gradual recognition of own distinct personality and growing acceptance of own solitary preferences.

\section{Access to Healthcare}

In the initial sessions of his therapy Richard reflected on his pre-existing beliefs about the undesirable and adverse aspects of social exposure, often resulting in the avoidance of, and disengagement from, any form of meaningful interpersonal interaction. Since the multidisciplinary mental health care had been readily available to Richard for numerous years prior to the commencement of the current psychological treatment, such prolonged social avoidance was conceptuallised as an internally generated barrier to seeking and accessing psychological help, and was then systematically addressed with cognitive and behavioural interventions throughout the course of his therapy.

The therapist often accentuated Richard's resilience in persisting with the treatment, although such engagement had not been perceived as corresponding with his pre-existing belief set, thus might have triggered considerable levels of ambiguity and discomfort. Despite such difficulties, typical for individuals with schizoid personality, Richard was able to develop a trusting therapeutic relationship and recognise the importance of receiving psychological care, which he expressed his gratitude for. He also stated he would not hesitate to reach out and seek further help in the future, should he become concerned about his emotional wellbeing again.

As an integral part of the multidisciplinary care package, Richard was offered psychiatric support. In his initial appointment with the team psychiatrist, Richard 
described his previous experience of discontinuing his pharmacological therapy with antidepressants, which had precipitated further deterioration in his mood. Richard was encouraged to consider recommencing such treatment to additionally address his chronically low mood, alongside the offered psychological therapy. However, as Richard expressed his considerable reservations regarding such pharmacological input, it was collaboratively agreed that his mental health would be regularly monitored by a psychiatric nurse, and another appointment with a psychiatrist would be scheduled, if CT proved insufficient as the sole therapeutic intervention.

\section{Discussion}

As explained by Renton and Mankiewicz (2015), individuals with SPD are often convinced that they are different, unlikable, and unable to fit within the wider community and social world, hence interpersonal interactions should be avoided. However, subjective rationales behind such interpersonal disengagement relate to a belief set, specific to SPD, often formed in the context of early life experiences. And these experiences, as established in literature reviewed by Martens (2010), appear to be characterised by the underlying theme of prolonged loneliness and social detachment.

The existing clinical literature appears to indicate that in individuals presenting with SPD, the creation of meaning might be an affect evoking experience, which would constitute a crucial stage in the process of change (Kramer and Meystre 2010). Thus, as demonstrated in the present article, the development of a mutual and compassionate understanding of underlying difficulties, establishment of a collaborative working alliance, and agreement on individually meaningful therapy goals, appear paramount for successful implementation of cognitive and behavioural interventions. This needs to be embedded in a functional therapeutic relationship and mutually shared narrative that support the client's individuality and respects their personality.

Further contribution the present case study attempts to make to the scarce literature on the subject of SPD, is to demonstrate that a clinically skilful implementation of cognitive behavioural intervention with schizoid individuals may lead to a considerable therapeutic change allowing an overall increase in reported quality of life and subjective satisfaction. Such improvements in psychosocial functioning would be achieved through a methodical implementation of cognitive restructuring of distressing appraisals of contextual circumstances and graded behavioural exposure to the previously avoided stimuli. Eventually, both cognitive and behavioural strategies, would result in the development of more compassionate understanding of own difficulties, considerable lowering in emotional distress, gradual improvements in coping with interpersonal interactions, and reinstatement of individually rewarding activities.

Such findings appear relevant in the context of current literature on the subject of psychological treatments of severe personality disorders, in which the development of self-reflective abilities in the supportive interpersonal environment 
of therapeutic relationship is perceived as having important clinical merit (Haliburn et al. 2018). In the current case, such functional level of self-reflection was achieved through an empathetic, collaborative and mutually respectful development of shared conceptualisation, and subsequently acted as a central intellectual precursor of a gradual cognitive and behavioural change, without the need to explicitly alter the individual's schizoid constitution.

Based on the case reported above, it seems plausible to conclude that cognitive understanding of SPD may offer a destigmatising, coherent and compassionate conceptualisation of emotional distress, behavioural disparity, and interpersonal indifference. Given the contextual narrative in western societies about interpersonal relationships being indispensable in all aspects of success, this novel conceptualisation of schizoid individuals may represent a unique opportunity for finding value in their own lives.

As the current knowledge related to psychological treatments of SPD appears somewhat underrepresented in the clinical and academic literature, it seems pertinent for clinicians and trainee therapists to remember that in SPD, based on a mutual understanding of the problematic aspects of individual functioning, an effective, person-centred and theory-led cognitive behavioural intervention can be delivered, and a gradual progress in one's psychosocial functioning might be achieved. Importantly, such progress can be accomplished without the need for addressing the underlying traits specific to schizoid personality. On the contrary, the individual reported in the present case study perceived the diagnosis of SPD as rather helpful and normalising.

Such experience of mental health diagnosis does not seem particularly uncommon in the context of a recent systematic review of qualitative literature on this subject, which highlights the importance of collaboration between individuals and services, establishment of helpful therapeutic rapport, timing and subjectively perceived accuracy of diagnosis, provision of relevant information, and subsequent focus on individual psychosocial recovery (Perkins et al. 2018).

\section{Limitations and Future Research}

As the current article reports a preliminary single subject evaluative implementation of CT for SPD, although our results seem clearly encouraging, ideally, further research should include larger-scale empirical studies of controlled nature, targeting a range of clinical presentations with different levels of social disengagement and interpersonal avoidance. Such studies would be essential in providing further systematic and generalised indications for clinical practice in SPD. However, as recruitment of schizoid individuals might prove difficult due to the typical personality traits affecting their interpersonal engagement, publication of further methodologically rigorous single subject design studies appears indispensable in the development of effective treatment models, hence should be encouraged.

It seems important to note that the reported intervention was undertaken with a relatively well functioning male adult of Caucasian origin, achieving a gradual 
progress in his psychosocial recovery, willing to engage in the process of therapeutic change, with no prior forensic history. Hence, a possible sample selectivity bias should be acknowledged. In order to accurately reflect the clinical reality of specialist services for individuals with complex personality disorders in diverse metropolitan communities, future studies would ideally need to include participants with chronic difficulties, representing different ethnic and cultural backgrounds. A greater understanding of effective cognitive interventions in complex schizoid presentations would likely equip clinicians working in the aforementioned specialism with further important therapeutic competencies, which would likely contribute to the enhancement of their clients' psychosocial recovery.

\section{Conclusion}

The paper demonstrates the applicability of cognitive and behavioural interventions in increasing psychosocial health of individuals diagnosed with SPD, whose interpersonal functioning would otherwise likely remain limited and restrict exposure to opportunities for achieving a gradual progress in their psychosocial recovery. The article reflects on the implications of the current study for psychological medicine practitioners working within the environment of community mental health settings.

\section{References}

Adshead G, Sarkar J (2012) The nature of personality disorder. Advances in Psychiatric Treatment 18(3): 162-172.

American Psychiatric Association (2013) Diagnostic and statistical manual of mental disorders, $5^{\text {th }}$ ed. Arlington, VA: American Psychiatric Association (APA).

Backman CL, Harris SR (1999) Case studies, single-subject research, and N of 1 randomized trials: Comparisons and contrasts. American Journal of Physical Medicine and Rehabilitation 78(2): 170-176.

Backman C, Harris SR, Chisholm JM, Monette AD (1997) Single-subject research in rehabilitation: $\mathrm{A}$ review of studies using $\mathrm{AB}$, withdrawal, multiple baseline and alternating treatments designs. Archives of Physical Medicine and Rehabilitation 78(10): 1145-1153.

Bateman A, Tyrer P (2004) Psychological treatment for personality disorder. Advances in Psychiatric Treatment 10(5): 378-388.

Beck AT, Davis DD, Freeman, A (Eds.) (2015) Cognitive therapy of personality disorders, $3^{\text {rd }}$ ed. New York, NY: The Guilford Press.

Coid J (2002) Personality disorders in prisoners and their motivation for dangerous and disruptive behaviour. Criminal Behaviour and Mental Health 12(3): 209-226.

Davison SE (2002) Principles of managing patients with personality disorder. Advances in Psychiatric Treatment 8(1): 1-9.

Derogatis LR (1993) Brief Symptom Inventory: Administration, scoring, and procedures manual, $4^{\text {th }}$ ed. Minneapolis, MN: Pearson.

Derogatis LR, Melisaratos N (1983) The Brief Symptom Inventory: An introductory report. Psychological Medicine 13(3): 595-605. 
Ekselius L, Tillfors M, Furmark T, Fredrikson M (2001) Personality disorders in the general population. DSM-IV and ICD-10 defined prevalence as related to sociodemographic profile. Personality and Individual Differences 30(2): 311-320.

Evershed S (2011) Treatment of personality disorder. Skills-based therapies. Advances in Psychiatric Treatment 17(3): 206-213.

Fagin L (2004) Management of personality disorders in acute care settings. Part 2: Less common personality disorders. Advances in Psychiatric Treatment 10: 100-106.

Farmer RF, Chapman AL (2002) Evaluation of DSM-IV personality disorder criteria as assessed by the Structured Clinical Interview for DSM-IV Personality Disorders. Comprehensive Psychiatry 43(3): 285-300.

Francis VM, Rajan P, Turner N (1990) British community norms for the Brief Symptom Inventory. British Journal of Clinical Psychology 29(1): 115-116.

Haliburn J, Stevenson J, Halovic S (2018) Integration in the psychodynamic psychotherapy of severe personality disorders: The conversational model. Journal of Personality Disorders 32(1): 70-86.

Johnson JJ, Smailes EM, Cohen P, Brown J, Bernstein DP (2000) Associations between four types of childhood neglect and personality disorder symptoms during adolescence and early adulthood. Findings of a community based longitudinal study. Journal of Personality Disorders 14(2): 171-187.

Joyce PR, McKenzie JM, Carter JD, Rae AM, Luty SE, Frampton CMA, Mulder RT (2007) Temperament, character and personality disorders as predictors of response to interpersonal psychotherapy and cognitive-behavioural therapy for depression. British Journal of Psychiatry 190(6): 503-508.

Kerimova M, Osmanli N (2016) The Brief Symptom Inventory: A validity-reliability study of a sample from Azerbaijan. Journal of Education and Training Studies 4(12): 153-159.

Kramer U, Meystre C (2010) Assimilation process in psychotherapy with a client presenting schizoid personality disorder. Swiss Archives of Neurology, Psychiatry and Psychotherapy 161(4): 128-134.

Martens WHJ (2010) Schizoid personality disorder linked to unbearable and inescapable loneliness. European Journal of Psychiatry 24(1): 38-45.

Mittal VA, Kalus O, Bernstein DP, Siever LJ (2007) Schizoid personality disorder. In W O'Donohue, KA Fowler, SO Lilenfeld (Eds.) Personality disorders: Toward the $D S M-V$, pp. 63-80. Thousand Oaks, CA: Sage Publications.

Offender Health Research Network (2012) Mental illness, personality disorder an violence: A scoping review. Manchester, UK: Offender Health Research Network.

Padesky CA (1993) Socratic questioning. Changing minds or guided discovery? Keynote address delivered at the European Congress of Behavioural and Cognitive Therapies, London, UK.

Pereda N, Forns M, Pero M (2007) Dimensional structure of the Brief Symptom Inventory with Spanish college students. Psicothema 19(4): 364-639.

Perez-Alvarez M. (2003) The schizoid personality of our time. International Journal of Psychology and Psychological Therapy 3(2): 181-194.

Perkins A, Ridler J, Browes D, Peryer G, Notley C, Hackmann C (2018) Experiencing mental health diagnosis: A systematic review of service user, clinician, and carer perspectives across clinical settings. The Lancet Psychiatry 5(9): 747-764

Renton JC, Mankiewicz PD (2015) Paranoid, schizotypal and schizoid personality disorders. In AT Beck, DD Davis, A Freeman (Eds.), Cognitive Therapy of Personality Disorders, $3^{\text {rd }}$ ed., pp. 244-275. New York, NY: The Guilford Press.

Ruz MEA, Lennie TA, Riegel B, McKinley S, Doering LV, Moser DK (2010) Evidence that the Brief Symptom Inventory can be used to measure anxiety quickly and 
reliably in patients hospitalized for acute myocardial infarction. Journal of Cardiovascular Nursing 25(2): 117-123.

Ryan C (2007) British outpatient norms for the brief symptom inventory. Psychology and Psychotherapy. Theory, Research and Practice 80(2): 183-191.

Samuels J, Eaton WW, Bienvenu J, Brown CH, Costa PT Jr, Nestadt G (2002) Prevalence and correlates of personality disorders in a community sample. British Journal of Psychiatry 180(6): 536-542.

Stevenson J, Broadaty H, Boyce P, Byth K (2011) Personality disorder co-morbidity and outcome: Comparison of three age groups. Australian and New Zealand Journal of Psychiatry 45(9): 771-779.

Triebwasser J, Chemerinski E, Roussos P, Siever LJ (2012) Schizoid personality disorder. Journal of Personality Disorders 26(6): 919-926.

World Health Organisation (1992) The ICD-10 classification of mental and behavioural disorders: Clinical descriptions and diagnostic guidelines. Geneva, Switzerland: World Health Organisation. 